Dicle University Journal of Engineering (DUJE)

web: http://dergipark.gov.tr/dumf

Araștırma Makalesi / Research Article

\title{
Yeşil Binalar için Analitik Ağ Süreci (AAS) Kullanılarak Yüklenici Seçimi
}

\section{Contractor Selection for Green Buildings Using the Analytic Network Process}

(ANP)

\section{Emre Caner Akçay ${ }^{*}$}

${ }^{1}$ Atılım Üniversitesi, İnşaat Mühendisliği Bölümü, Ankara, caner.akcay@ atilim.edu.tr

\begin{tabular}{|c|c|}
\hline MAKALE BİLGİLERİ & ÖZET \\
\hline Makale geçmişi: & \multirow{6}{*}{ 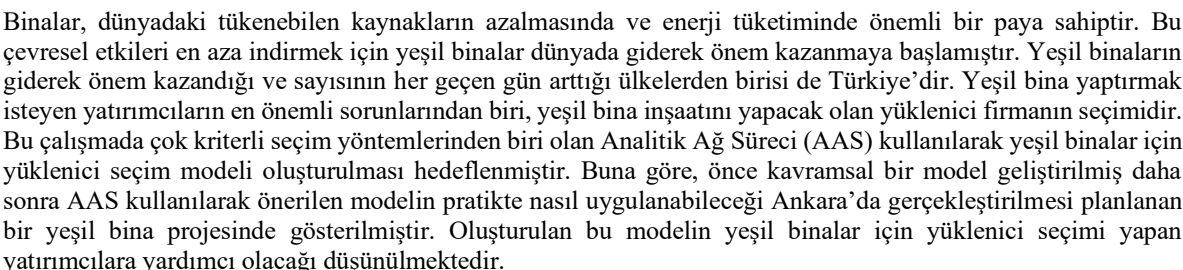 } \\
\hline Geliş: 19 Aralık 2019 & \\
\hline Düzeltme: 9 Mayıs 2020 & \\
\hline Kabul: 11 Mayıs 2020 & \\
\hline Anahtar kelimeler: & \\
\hline AAS, yüklenici seçimi, yeşil bir & \\
\hline
\end{tabular}

Doi: 10.24012/dumf.661711

\begin{tabular}{ll}
\hline ARTICLE INFO & $\begin{array}{l}\text { ABSTRACT } \\
\text { Article history: }\end{array}$ \\
$\begin{array}{l}\text { Buildings have a significant effect on the reduction of the resources and energy consumption in the world. In order } \\
\text { to minimize these environmental impacts, green buildings have gained importance in the world. Turkey is one of } \\
\text { these countries, where the number of green buildings have been increased day by day. Therefore, the main question } \\
\text { for investors is how they can select the appropriate contractor for the green building construction. The objective } \\
\text { of this study is to develop an Analytic Network Process (ANP) based selection model that can be used to select } \\
\text { Accepted: } 11 \text { May } 2020\end{array}$ & $\begin{array}{l}\text { the appropriate contractor for the green building construction. To achieve this aim, the criteria in the selection } \\
\text { process are identified, the relationships among the criteria are determined, and the ANP based selection model is } \\
\text { constructed. }\end{array}$
\end{tabular}

building

\footnotetext{
* Sorumlu yazar / Correspondence

Emre Caner AKCAY

$\bowtie$ caner.akcay@atilim.edu.tr
} 


\section{Giriș}

Binalar, dünyadaki enerji tüketiminin artmasında ve tükenebilen kaynakların azalmasında çok önemli bir paya sahiptir [1]. Yapılan araştırmalar, binaların dünya genelindeki enerji tüketiminin \%40'1na sebep olduğunu göstermektedir [2]. Binalar, enerji tüketimine ek olarak $\mathrm{CO}_{2}$ emisyonu, su kullanımı ve katı atıkların kullanımını da önemli ölçüde arttırmaktadır [3]. Bu çevresel etkileri en aza indirmek ve çevreyi korumak için yeşil binalar dünyada giderek önem kazanmaya başlamıștır. Yeşil binaların giderek önem kazandığ ülkelerden birisi de Türkiye'dir. 2019 Nisan ay1 itibariyle Türkiye'deki sertifikalı yeşil bina sayısı 400'e çıkarak, dünyada bu alanda 6. sırada bulunmaktadır [4]. Türkiye'deki yeşil bina sayısının önümüzdeki yıllarda önemli oranda artacağ1 öngörülmektedir. Özellikle yeşil bina yaptırmak isteyen yatırımciların en önemli sorunlarından biri de, yeşil binayı inşa edecek yüklenici firmanın seçimidir. Çoğu zaman sadece en düşük fiyat kriteri ile yüklenicinin seçilmesi projelerin başarısız olmasına sebebiyet vermektedir [5]. Tek bir kriter yerine, yüklenici seçiminde önemli olan tüm kriterlerin belirlenmesi, daha sonra ise bu kriterlerin tamamının göz önünde bulundurularak yüklenici seçiminin yapılması çok daha güvenilir sonuçlar verebilecektir. $\mathrm{Bu}$ çalışmada, çok kriterli seçim yöntemlerinden biri olan Analitik Ağ Süreci (AAS) kullanılarak yeşil binalar için yüklenici seçim modeli oluşturulması hedeflenmiştir. Buna göre, önce kavramsal bir model geliştirilmiş daha sonra AAS kullanılarak önerilen modelin pratikte nasıl uygulanabileceği Ankara'da gerçekleştirilmesi planlanan bir yeşil bina projesinde gösterilmiştir. Makalede öncelikle AAS yöntemi kullanılarak gerçekleştirilmiş benzer çalışmalar irdelenecek, daha sonra da yeşil binalar için yüklenici seçiminde kullanımı gerçek bir proje üzerinden anlatılacaktır.

\section{Analitik Ăg Süreci (AAS) ile ilgili literatür bulguları}

Çok kriterli seçim yöntemlerinden en yaygın olarak kullanılan yöntemlerin başında Saaty [6] tarafından önerilen analitik hiyerarşi süreci (AHS) gelmektedir. Bu süreçteki temel prensip; seçim kriterlerinin belli bir hiyerarşik düzene göre siralanması, daha sonrasinda ise her bir kriterin bir üst hiyerarşideki kontrol kriterine göre önem derecesinin belirlenmesidir. Analitik Hiyerarşi Süreci her ne kadar geniş bir kullanım alanına sahip olsa da; seçim kriterleri arasındaki etkileşimi ve bağımlılıkları göstermemesi bu yöntemin en büyük dezavantajı olarak görülmekte ve kullanım alanını kısıtlamaktadır. Analitik hiyerarşi sürecinin genelleştirilmiş şekli olan ve Saaty [7] tarafından sunulan Analitik A $\breve{g}$ Süreci (AAS), AHS yönteminin aksine karar vericilere seçim kriterleri arasındaki etkileşimi ve bağımlılıkları gösterme imkanı sağlamaktadır.

Yapım ve proje yönetimi alanında Analitik A $\breve{g}$ Süreci kullanılarak yapılan pek çok sayıda çalışma mevcuttur. Literatürdeki bu çalışmalar seçim problemleri, performans değerlendirmeleri ve risk değerlendirmeleri olmak üzere 3 ana başlık altında toplanabilmektedir.İnşaat sektöründe farklı seçim problemlerine AAS kullanılarak güvenilir çözümler elde edilmiştir. Bu kapsamda Hasnain vd. [8] yol inşaat projeleri için yüklenici seçimini sağlayan AAS temelli bir karar destek sistemi kurmuştur. El-Abbasy vd. [5] AAS yöntemi kullanarak yol inşaatı projeleri için ana yüklenici seçimi yapan bir model oluşturmuştur. Cheng ve Li [9] AAS yönteminden faydalanarak yüklenici firma seçimi için bir model önermiştir.Ozcan-Deniz ve Zhu [10] çevre dostu karayolu inşaat yöntemi seçimini AAS yöntemi kullanarak yapmıştır; Reisi vd. [11] AHS ve AAS kullanılarak endüstriyel inşaat sahası seçimi için bir yöntem ortaya koymuştur. Literatür bulguları, yeşil bina ve/veya inşaat ile ilgili herhangi bir çalışmanın henüz yapılmamış olduğunu ve bu alanda bir eksiklik olduğunu göstermektedir.

Literatürdeki AAS kullanılarak performans değerlendirmesini gerçekleştiren çalışmalarise temelde farklı şirket/sistem/yönteme ilişkin performansın tahmin edilmesini içermektedir. Ozorhon vd. [12] AAS yöntemini kullanarak uluslararası inşaat ortak girişimlerin performanslarını tahmin eden bir model geliştirmiştir; Shahpari vd. [13] prefabrik ve yerinde inşaat sistemlerinin verimliliğini AAS yöntemi kullanarak değerlendirmiştir; Li vd. [14] AAS temelli kapsamlı bir değerlendirme modeli oluşturarak yalın inşaat yönetim performanslarını değerlendirmiştir; Erdem ve Ozorhon [15] gayrimenkul projelerin başarılarını 
değerlendirmek için AAS yönteminden faydalanmıştır.

Literatürde AAS kullanılarak risk değerlendirmesi yapılan çalışmalar da mevcuttur. Yang vd. [16] AAS yöntemi kullanarak metro istasyon inşaatlarının güvenlik risklerini değerlendirmiştir; Do vd. [17] Vietnam'daki uluslararası inşaat ortak girişimlerinin risk değerlendirmesini gerçekleştirmek için AAS yönteminden faydalanmıştır; Kiani Mavi ve Standing [18] bulanık AAS yaklaşımı kullanarak sürdürülebilir proje yönetimindeki kritik başarı faktörlerini belirlemiş̧tir; Bu-Qammaz vd. [19] uluslararası inşaat projelerinin risk değerlendirmesini AAS kullanarak gerçekleştirmişlerdir.

Literatürdeki çalışmalarda da görüldüğü üzere AAS yöntemi inşaat sektöründe çok farklı problemlere çözüm getirmek için kullanılmıştır; fakat yeşil bina projeleri için yapılacak olan yüklenici firma seçimleriyle ilgili herhangi bir çalışma bulunmamaktadır. Buradan hareketle; yapılan bu araştırmada, öncelikle yeşil binaların inşaatı için yüklenici seçim kriterleri belirlenecek, daha sonra ise analitik ağ süreci kullanılarak bir seçim modeli oluşturulacaktır.

\section{Yeşil Binalar için Yüklenici Seçim Modelinin Oluşturulması}

Bu çalışmada, AAS yöntemi kullanılarak yeşil binaların inşaatı için yüklenici seçimine olanak sağlayan model 4 temel aşamada oluşturulacaktır. İlk aşamada yüklenici seçimini belirleyen kriterler belirlenerek modelin ağ yapısı oluşturulacak, ikinci aşamada olușturulan model için karşılaştırma matrisleri oluşturulup doldurulacak, üçüncü aşamada modelin süpermatriksleri oluşturularak yüklenici seçimini belirleyen her bir kriterin önem derecesi belirlenecek, son aşamada ise her bir kriterin önem derecesi kullanılarak yüklenici seçimi yapilacaktır.

\section{Modelin A $\breve{g}$ Yapısının Kurulması}

Yeşil Binalar için yüklenici seçimini sağlayan bir modelin oluşturulması için öncelikle bu seçimi etkileyen kriterlerin belirlenmesi gerekmektedir. Yapılan bu çalışmada, kriterlerin belirlenmesi için daha önce yeşil bina inşaatı yaptırmış 10 yatırımcı firma yetkilileri ile yarı-yapılandırılmış mülakatlar gerçekleştirilmiştir. Mülakatlarda, katılımcılara geçmișteki tecrübelerinden faydalanarak yeşil bina inşaatı için yüklenici seçiminde önemli gördükleri kriterleri bir liste halinde hazırlamaları istenmiştir. Anket sonucunda katılımcilar tarafindan belirlenen bütün kriterler, öncelikle birleştirilerek tek bir kriter listesi haline getirilmiş (Tablo 1), daha sonra ise ilgi alanlarına göre finansal kriterler, kalite ve teknoloji kriterleri, işin yapımı ile ilgili kriterler ve deneyim kriterleri olmak üzere 4 ana başlık altında gruplandırılmıştır. Bu kriterlerden "Şirketin Finansal Durumu" ile ilgili şunu belirtmek gerekir ki; bu kriter "Ciroyu gösteren gelir tablosu" ve "Bilanço verilerinden oluşan cari oranı" olarak iki ayrı kriterin birleşimi olarak tek bir kriter olarak kullanılmıştır.

Tablo 1. Yeşil Binalar için yüklenici seçim kriterleri

\section{Seçim Kriterleri}

Deneyime İlişkin referans listesi

İnşaatı yapılmış yeşil bina sayısı

İş deneyim belgesi toplam tutarı

Şirketle daha önce iş yapılıp yapılmaması

Banka referans mektup toplam tutarı

Şirketin finansal durumu

Taahhüt edilen iș bitirme süresi

Teklif edilen fiyat

Şirketin sahip olduğu ekipman sayısı ve teknolojisi

Şirketin sahip olduğu ISO belgeleri

AAS yönteminin uygulanabilmesi için belirlenen kriterlerin a ğ yapısının oluşturulması gerekmektedir. $\mathrm{Bu}$ ağ yapısının hazırlanabilmesi için, öncelikle her bir kriterin birbirleri ile etkileşiminin belirlenmesi gerekmektedir. $\mathrm{Bu}$ amaçla, daha önce mülakatlara katılmış olan 10 yatırımcı firma temsilcisinin katılımı ile bir beyin firtınası oturumu gerçekleştirilmiştir. $\mathrm{Bu}$ oturumda öncelikle katılımcıların Tablo 1 ile ilgili görüşleri alınmış, tüm katılımcıların hemfikir olduğu kriterlerin aralarındaki ilişkilerin belirlenmesi amaciyla 10x10'luk bir matris dağıtılarak katılımcılardan doldurmaları 


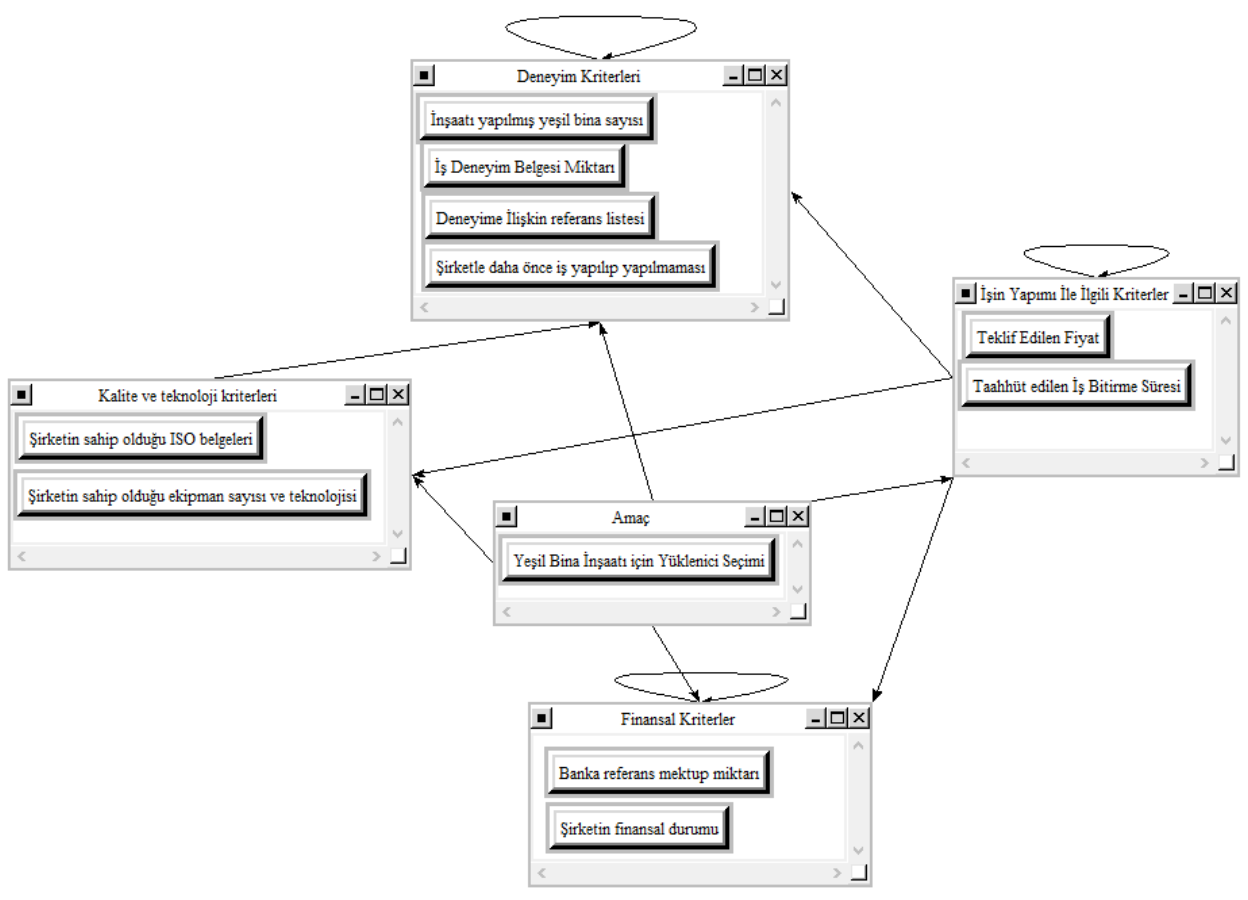

Şekil 1. Modelin A $\breve{g}$ Yapısı

istenmiştir. Beyin fırtınası sonucunda çıkan ve her bir kriterin birbirleri ile etkileşimini gösteren modelin ağ yapısı Şekil 1'de gösterilmiştir.

\section{Karşılaştırma Matrislerinin Oluşturulması}

Saaty [20] tarafindan belirtildiği üzere ikili karş1laştırmalar iki elemandan birinin sistemdeki üçüncü bir elemana (kontrol kriterine) göre göreceli etkisini bulmak için gerçekleştirilir. $\mathrm{Bu}$ etkiyi derecelendirmek için AHS'de olduğu AAS'de de Saaty [21] tarafından önerilen 1-9 skalası kullanılmakta ve bu skaladaki her bir değerin önem derecesi Tablo 2'de gösterilmektedir.

Tablo 2. Temel Ölçek [21]

\begin{tabular}{cll}
\hline $\begin{array}{c}\text { Önem } \\
\text { Derecesi }\end{array}$ & Tanım & \multicolumn{1}{c}{ Açılama } \\
\hline & Eşit öneme sahip & $\begin{array}{l}\text { İki kriter de eşit } \\
\text { öneme sahip }\end{array}$ \\
2 & Az önemli & $\begin{array}{l}\text { Bir kriter diğer kritere } \\
\text { göre biraz daha } \\
\text { önemli }\end{array}$ \\
3 & Orta önemli & \\
4 & $\begin{array}{l}\text { Ortadan biraz } \\
\text { fazla önemli }\end{array}$ & \\
\hline
\end{tabular}

\begin{tabular}{lll}
\hline 5 & Kuvvetli önemli & $\begin{array}{l}\text { Bir kriter diğer kritere } \\
\text { göre kuvvetli derece } \\
\text { daha önemli }\end{array}$ \\
6 & $\begin{array}{l}\text { Kuvvetliden } \\
\text { biraz fazla } \\
\text { önemli }\end{array}$ & Bir kriter diğer kritere \\
7 & $\begin{array}{l}\text { Çok kuvvetli } \\
\text { önemli }\end{array}$ & $\begin{array}{l}\text { göre çok kuvvetli } \\
\text { derece daha önemli }\end{array}$ \\
8 & $\begin{array}{l}\text { Çok çok } \\
\text { kuvvetli önemli }\end{array}$ & Bir kriter diğer kritere \\
9 & Aşı̈rı önemli & $\begin{array}{l}\text { göre ärı şiddetli } \\
\text { daha önemli }\end{array}$ \\
\hline
\end{tabular}

Matrisleri oluştururken dikkat edilmesi gereken bir diğer önemli nokta ise matrislerin tutarlık oranıdır. Bu oran matrisin içerisindeki değerlerin tutarlı olup olmadığını göstermektedir. Saaty [22] tarafindan belirtildiği üzere her bir matrisin tutarlık oranı 0.1'den küçük olmalıdır. Yapılan bu çalışmada, oluşturulan modelin ağ yapısı kullanılarak toplamda 32 tane karşılaştırma matrisi oluşturulmuştur. $\mathrm{Bu}$ matrislerin doldurulması için ise, ilk beyin firtınası oturumu yapılan katılımcılarla bir başka beyin fırtınası oturumu düzenlenmiştir. Düzenlenen bu oturumda bütün karşılaştırma matrisleri her biri katılımcıya dağıtılmış, daha sonra ise her bir 
matris için ayrı tartıșmalar yapılarak bütün matrisler düzenlenen beyin firtınası oturumu sonucunda doldurulmuştur. Doldurulma işlemi yapılırken matrislerin tutarlık oranları da kontrol edilmiş ve hepsinin 0.1 'den küçük olduğu görülmüştür.

\section{Süpermatrislerin Oluşturulması}

Oluşturulan model için karşılaştırma matrisleri elde edildikten sonra, üçüncü aşamada süpermatrislerin oluşturulması ve bu matrislerden faydalanarak her bir kriterin önem derecesinin belirlenmesi gerekmektedir. Saaty [23] tarafından belirtildiği üzere AAS yönteminde üç aşamalı süpermatris hesaplaması mevcuttur. Bunlar sırasıyla; ağırlıklandırılmamış süpermatris, ağırlıklandırılmış süpermatris ve limit süpermatristir. İlk aşamada, birbirlerini etkileyen elementlerin karşılaştırılmalarının sonucunda elde edilen yerel önceliklerden faydalanılarak ağırlıklandırılmamış süpermatris meydana getirilmektedir. İkinci aşamada, ağırlaklandırılmamış süpermatris değerleri ait oldukları grup ağırlıklarıyla çarpılması sonucu ağırlıklandırılmış süpermatris oluşturulmaktadır. Son aşamada ise, ağırlıklandırılmış süpermatrisin bütün kolonları sabit bir değere gelene kadar kuvvetlerinin alınması sonucu limit süpermatris elde edilmektedir. $\mathrm{Bu}$ süpermatrislerin oluşturulma işlemi Saaty [23] tarafından geliştirilen SUPER DECISIONS adlı bir yazılım yardımıyla elde edilmektedir. Oluşturulan bu üç süpermatristen en önemli olanı limit süpermatrisidir. $\mathrm{Bu}$ matris, her bir seçim kriterinin ağırlığını vererek bir nevi seçim kriterlerinin önem değerlerini göstermektedir. Yapılan bu çalışmada, oluşturulan modele ait SUPER DECISIONS adlı yazılım kullanılarak elde edilen limit matrisin ekran görüntüsü Şekil 2 'de gösterilmektedir.

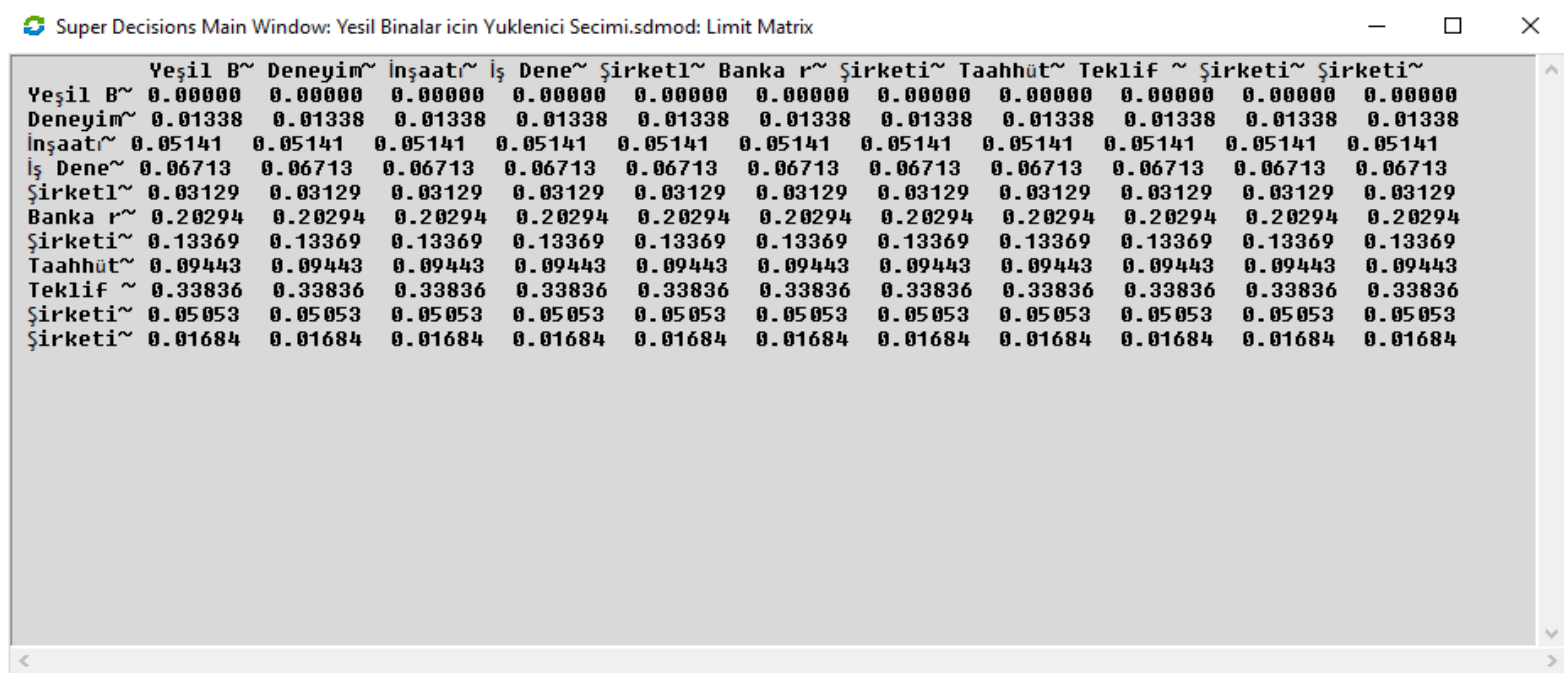

Şekil 2. Modelin Limit Matrisi

Limit süpermatristen elde edilen her bir kriterin önem derecesi ise Tablo 3'te gösterilmektedir. Bu tabloya göre yüklenici seçiminde en önemli kriter, beklenildiği üzere teklif edilen fiyattır. İkinci önemli kriter ise şirketin sahip olduğu banka referans mektup toplam tutarı olarak belirlenmiștir. Önem derecesi en düșük olan kriter ise şirketin sahip olduğu ISO belgeleridir. Çıan bu sonuçlar ve her bir kriterin önem derecesi beyin firtınası oturumuna katılan katılımcılara gösterilmiș ve değerlerin mantıklı olup olmadığı sorulmuştur. Katılımcılar, değerlerin mantıklı olduğu görüşünde birleşmiş ve çalıșmanın bir sonraki aşamasında kullanılmasını uygun bulmuştur.

Tablo 3. Kriterlerin önem dereceleri

Kriter

Seçim Kriterleri Ăğılıkları

\begin{tabular}{|c|c|}
\hline $\begin{array}{l}\text { Deneyime İlişkin referans } \\
\text { listesi }\end{array}$ & 0.013 \\
\hline $\begin{array}{l}\text { İnşaatı yapılmış yeşil bina } \\
\text { saylsı }\end{array}$ & 0.051 \\
\hline $\begin{array}{c}\dot{I}_{\text {Ş }} \text { deneyim belgesi toplam } \\
\text { tutarl }\end{array}$ & 0.067 \\
\hline
\end{tabular}




\begin{tabular}{ll}
\hline \multicolumn{2}{c}{ Şirketle daha önce iş yapılıp } \\
yapılmaması & 0.031 \\
$\quad$ Banka referans mektup toplam & \\
tutarı & 0.203 \\
$\quad$ Şirketin finansal durumu & 0.134 \\
$\quad$ Taahhüt edilen iş bitirme süresi & 0.094 \\
$\quad \begin{array}{l}\text { Teklif edilen fiyat } \\
\text { Şirketin sahip olduğu ekipman }\end{array}$ & 0.338 \\
$\begin{array}{l}\text { saylsı ve teknolojisi } \\
\quad \text { Şirketin sahip olduğu ISO }\end{array}$ & 0.051 \\
belgeleri & 0.017 \\
\hline
\end{tabular}

\section{Yüklenici Seçiminin Yapılması}

Yeşil Bina için yüklenici seçimi yapılan modelin son aşaması her bir yüklenici adayının teklif puanının belirlenerek en yüksek puana sahip yüklenici adayının yüklenici olarak seçilmesini kapsamaktadır. Teklif puanı hesaplama işlemi için; öncelikle her bir yüklenici adayından bütün yüklenici seçim kriterleri ile ilgili bilgi istenilecek, daha sonra ise her bir kriter 1-5 skalasında puanlandırılacak ve bu puanlar AAS sonucu elde edilen her bir seçim kriterinin önem derecesi ile çarpılarak, çıkan bütün sonuçlar toplanacaktır. Örnek bir teklif puanı hesaplama işlemi Denklem 1'de gösterilmektedir:

Teklif Puanı Firma $\mathrm{A}=\left(\mathrm{p}_{1 \mathrm{~A}} \mathrm{x} \mathrm{d}_{1}\right)+\left(\begin{array}{lll}\mathrm{p}_{2 \mathrm{~A}} \mathrm{~A} & \mathrm{x} & \mathrm{d}_{2}\end{array}\right)$ $+\ldots \ldots . . .+\left(\mathrm{p}_{10 \mathrm{~A}} \times \mathrm{d}_{10}\right)$

kriterinin puan 1 derecesi

$\mathrm{d}_{1}=$ Birinci seçim kriterinin önem kriterinin puan 1

$\mathrm{p}_{2 \mathrm{~A}}=\mathrm{A}$ firması için ikinci seçim derecesi

$\mathrm{d}_{2}=$ İkinci seçim kriterinin önem kriterinin puanı

$\mathrm{p}_{10 \mathrm{~A}}=\mathrm{A}$ firması için onuncu seçim derecesi

$\mathrm{d}_{10}=$ Onuncu seçim kriterinin önem

Puanlar belirlenirken yardımcı olması için aşağıdaki yönlendirmeler oluşturulmuştur :
- Deneyime ilişkin referans listesi kriteri doldurulurken yüklenici firmanın daha önce kaç farklı firmaya iş yaptığı yazılacaktır.

- İnşaatı yapılmış yeşil bina sayısı kriteri doldurulurken, yüklenici firma tarafindan daha önce yapılmış olan toplam yeşil bina sayıs1 yazılacaktır.

- Şirketin finansal durumu kriteri, şirketin cirosu ile cari oranına bakılarak bir finans uzmanı tarafindan çok kötü, kötü, orta, iyi ya da çok iyi olarak derecelendirilecektir.

- Şirketin sahip olduğu ekipman sayısı ve teknolojisi kriteri doldurulurken şirketin sahip olduğu ekipmanların toplam parasal değeri yazılacaktır.

- Daha sonra, parasal veya adet olarak yapılan tüm değerlendirmeler 1-5 ölçeğine taşınarak birbiri ile tutarlı hale getirilecektir.

\section{Modelin Test Edilmesi}

Geliştirilen bu yüklenici seçim modeli, Ankara'da yapılması planlanan bir yeşil bina projesi için test edilmiştir. Projeyi yapmaya 3 farklı yüklenici firma talip olmuştur. Her bir firmaya ait seçim kriter bilgileri alınmış, Tablo 4'te görüldüğü üzere ilk kolona her bir kriterin gerçek değerleri yazılmış, ikinci kolonlara ise şirket tarafından verilen gerçek değerlere göre 15 skalasında puan verilmiştir. Kriterler puanlandırılırken; 3 firmadan o kriterle ilgili en avantajlı teklif verene 5 puan verilmiş, diğer firmaların o kriterle ilgili teklifleri ona göre puanlandırılmıştır. Örneğin; "Banka Referans Mektup Toplam Tutarı" kriterini puanlandırırken; A Firmasının Banka Referans Mektup Toplam Tutarına (30.000.000 TL) 5 puan verilmiş, B Firmasının Banka Referans Mektup Toplam Tutarına (25.000.000 TL) 4 puan verilmiş, C Firmasının Banka Referans Mektup Toplam Tutarına (15.000.000 TL) 3 puan verilmiştir. Bu kriterlerden "Şirketle daha önce iş yapılıp yapılmaması" kriteri puanlandırılırken; şirketle daha önce iş yapılmışsa 5 puan, yapılmamışsa 1 puan verilmiştir. Her bir seçim kriteri puanlandırıldıktan sonra ortaya çıkan teklif puanları Tablo 4'te gösterilmiştir. 
Tablo 4. Örnek proje için teklif puanları

\begin{tabular}{|c|c|c|c|c|c|c|c|}
\hline \multirow{2}{*}{$\begin{array}{l}\text { Seçim } \\
\text { Kriterleri }\end{array}$} & \multirow[b]{2}{*}{$\begin{array}{l}\text { Kriter } \\
\text { Ağırlıkları }\end{array}$} & \multicolumn{2}{|c|}{ Firma A } & \multicolumn{2}{|c|}{ Firma B } & \multicolumn{2}{|c|}{ Firma C } \\
\hline & & \begin{tabular}{|l} 
Gerçek \\
Değerler
\end{tabular} & Puan & $\begin{array}{l}\text { Gerçek } \\
\text { Değerler }\end{array}$ & Puan & \begin{tabular}{|l} 
Gerçek \\
Değerler
\end{tabular} & Puan \\
\hline $\begin{array}{l}\text { Deneyime } \\
\text { Illişkin referans } \\
\text { listesi }\end{array}$ & 0.013 & 5 Firma & 4 & 2 Firma & 2 & 6 Firma & 5 \\
\hline $\begin{array}{l}\text { İnşaatı yapılmış } \\
\text { yeşil bina sayısı }\end{array}$ & 0.051 & 2 Bina & 5 & 0 & 1 & 1 Bina & 3 \\
\hline $\begin{array}{l}\text { Toplam iş } \\
\text { deneyim belgesi } \\
\text { toplam tutarı }\end{array}$ & 0.067 & $15.000 .000 \mathrm{TL}$ & 5 & $5.000 .000 \mathrm{TL}$ & 2 & $16.000 .000 \mathrm{TL}$ & 5 \\
\hline $\begin{array}{l}\text { Şirketle daha } \\
\text { önce iş yapılıp } \\
\text { yapılmaması }\end{array}$ & 0.031 & Yap1lmad1 & 1 & Yap1lmad1 & 1 & Yap1lmad1 & 1 \\
\hline $\begin{array}{l}\text { Banka referans } \\
\text { mektup toplam } \\
\text { tutarı }\end{array}$ & 0.203 & $30.000 .000 \mathrm{TL}$ & 5 & $25.000 .000 \mathrm{TL}$ & 4 & $15.000 .000 \mathrm{TL}$ & 3 \\
\hline $\begin{array}{l}\text { Şirketin finansal } \\
\text { durumu }\end{array}$ & 0.134 & Çok iyi & 5 & Orta & 3 & İyi & 4 \\
\hline $\begin{array}{l}\text { Taahhüt edilen } \\
\text { İș Bitirme Süresi }\end{array}$ & 0.094 & 150 gün & 4 & 180 gün & 2 & 140 gün & 5 \\
\hline $\begin{array}{l}\text { Teklif edilen } \\
\text { Fiyat }\end{array}$ & 0.338 & $10.000 .000 \mathrm{TL}$ & 4 & 9.000.000 TL & 5 & $11.000 .000 \mathrm{TL}$ & 3 \\
\hline $\begin{array}{l}\text { Şirketin sahip } \\
\text { olduğu ekipman } \\
\text { sayıs1 ve } \\
\text { teknolojisi }\end{array}$ & 0.051 & $20.000 .000 \mathrm{TL}$ & 5 & 2.000.000 TL & 1 & $5.000 .000 \mathrm{TL}$ & 3 \\
\hline $\begin{array}{l}\text { Şirketin sahip } \\
\text { olduğu ISO } \\
\text { belgeleri }\end{array}$ & 0.017 & $\begin{array}{l}\text { ISO 9001, ISO } \\
14001\end{array}$ & 5 & Yok & 1 & $\begin{array}{l}\text { ISO 9001, ISO } \\
14001\end{array}$ & 5 \\
\hline & & Teklif Puanı & 4.43 & Teklif Puanı & 3.40 & Teklif Puanı & 3.45 \\
\hline
\end{tabular}

Buna göre, A Firması 4.43 puanla, 3 yüklenici aday firma arasından 1. firma olmuştur, dolayısıyla oluşturulan bu modele göre en yüksek puana sahip olan A firmasının yüklenici firma olarak seçilmesi gerekmektedir. Bu örnek proje için sadece teklif edilen fiyata bakılarak yüklenici seçimi yapılsaydı B firmasının seçilmesi gerekiyordu, ancak tek bir kriter yerine birden çok kriter kullanılarak ve AAS yardımıyla modellenerek daha kapsamlı bir seçim yapılması sağlanmıştır.

\section{Sonuçlar}

Yapılan bu çalışmada, AAS yöntemi kullanılarak yeşil binalar için yüklenici seçimine olanak sağlayan bir model hazırlanmıştır. Bu modelin hazırlanması için sırasıyla yüklenici seçimine etki eden kriterler belirlenmiş, kriterler arasındaki etkileşimler saptanmış, modelin a ̆g yapısı oluşturulmuş, SUPER DECISIONS adlı yazılım kullanılarak süpermatrisler oluşturulmuş, bu süpermatrisler kullanılarak her bir kriterin önem derecesi bulunmuş, bu önem dereceleri kullanılarak yüklenici adayı her bir firmanın teklif puanı bulunmuştur. Yeşil binalar için yüklenici seçiminde en önemli iki seçim kriteri "Teklif edilen fiyat" ve "Banka referans mektup 
toplam tutarı" çıkmıştır. Bunun yanında; yeşil binaların yüklenici seçimi için iki spesifik kriterin ("İnşaatı yapılmış yeşil bina sayısı" ve "Şirketin sahip olduğu ekipman sayısı ve teknolojisi”) AAS kullanılarak oluşturulan modelde yüklenici seçimine toplamda yaklaşık olarak \% 10 etki ettiği görülmektedir. Her ne kadar "Teklif edilen fiyat" kriteri yapılan bu çalışmada en önemli kriter olarak belirlense de, AAS kullanılarak oluşturulan model sayesinde tek bir seçim kriterinden ziyade diğer kriterlerin de yüklenici seçimine etki ettiği görülmüştür. Oluşturulan bu model, Ankara'da yapılması düşünülen bir ofis binası için test edilmiş ve modelin başarıyla çalıştı̆̆1 görülmüştür. Hazırlanan bu modelin yeşil bina inşaatı yapmayı düşünen yatırımcılara yüklenici firma seçimi aşamasında kolaylık sağlayacağı düşünülmektedir. Ancak çalışma bulguları değerlendirilirken göz önünde bulundurulması gereken bazı noktalar da bulunmaktadır. Hazırlanan bu modelin seçim kriterleri ve her bir kriterin puanı belirlenirken öznel yargılar kullanılmıştır, ileriki çalışmalarda katılımcı sayısı arttırılarak ve Delphi benzeri yöntemler kullanılarak bu öznelliğin azaltılması mümkün olabilir.

\section{Kaynaklar}

[1] Perez-Lombard, L., Ortiz, J., Pout, C., (2008). A review on buildings energy consumption information, Energy and Buildings, 40:394-398.

[2] Yas, Z., Jaafer, K., (2020). Factors influencing the spread of green building projects in the UAE, Journal of Building Engineering, 27(100894)

[3] Cao, X., Xilei, D., Liu, J., (2016). Building energyconsumption status worldwide and the state-of-the-art technologies for zero-energy buildings during the past decade, Energy and Buildings, 128:198-213.

[4] Toki Haber. (2019). Türkiye yeşil bina sayısında Avrupa lideri - TOKI Haber. [internet] Site adresi https://www.tokihaber.com.tr/haberler/turkiye-yesil-binasayisinda-avrupa-lideri/ [Son erişim tarihi 18 Aralık 2019].

[5] El-Abbasy, M. S., Zayed, T., Ahmed, M., Alzraiee, H., Abouhamad, M., (2013). Contractor selection model for highway projects using integrated simulation and analytic network process, J. Constr. Eng. Manage., 139 (7): 755-767.

[6] Saaty, T. L. (1980). The analytic hierarchy process, McGrawHill, New York.

[7] Saaty, T. L. (1996). Decision making with dependence and feedback: The analytic network process, RWS Publications, Pittsburgh.

[8] Hasnain, M., Thaheem, M. J., Ullah, F., (2018). Best Value Contractor Selection in Road Construction Projects:ANPBased Decision Support System, Int. J. Civ. Eng., 16:695-714.
[9] Cheng, E., Li, H., (2004). Contractor selection using the analytic network process, Constr. Manage. Econ., 22(10):1021-1032

[10] Ozcan-Deniz, G., Zhu, Y., (2015). A Multi-Objective Decision-Support Model for Selecting Environmentally Conscious Highway Construction Methods, Journal of Civil Engineering and Management, 21(6):733-747.

[11] Reisi, M., Afzali, A., Aye, L., (2018). Applications of analytical hierarchy process (AHP) and analytical network process (ANP) for industrial site selections in Isfahan, Iran, Environmental Earth Sciences, 77(14).

[12] Ozorhon, B., Dikmen, I., Birgonul, M. T., (2007). Using analytic network process to predict the performance of international construction joint ventures, Journal of Management in Engineering, 23(3):156-163.

[13] Shahpari, M., Saradj, F. M., Pishvaee, M. S., Piri, S., (2020). Assessing the productivity of prefabricated and in-situ construction systems using hybrid multi-criteria decision making method, Journal of Building Engineering, 27(100979).

[14] Li, X.K., Wang, X. M., Lei, L., (2019). The application of an ANP-Fuzzy comprehensive evaluation model to assess lean construction management performance, Engineering, Construction and Architectural Management.

[15] Erdem, D., Ozorhon, B., (2015). Assessing Real Estate Project Success Using an Analytic Network Process, Journal of Management in Engineering, 31(4):04014065.

[16] Yang, T., Song, P., Liu, J., Wang, M., (2019). The assessment of metro station construction safety risk based on ANP-grey clustering method, Conference Proceedings of the 7th International Symposium on Project Management, ISPM 2019. pp. $153-158$

[17] Do, S. T., Likhitruangsilp, V., Kiet, T. T., Nguyen, P. T., (2017). Risk assessment for international construction joint ventures in Vietnam, International Journal of Advanced and Applied Sciences, 4(6):104-114

[18] Kiani Mavi, R., Standing, C., (2018). Critical success factors of sustainable project management in construction: A fuzzy DEMATEL-ANP approach, Journal of Cleaner Production, 194:751-765.

[19] Bu-Qammaz, A. S., Dikmen, I., Birgonul, M. T., (2009). Risk assessment of international construction projects using the analytic network process, Can. J. Civ. Eng., 36(7), 1170-1181.

[20] Saaty, T.L. (2005). Theory and applications of the Analytic Network Process: decision making with benefits, opportunities, costs, and risks, RWS Publications, Pittsburgh, Penn., USA.

[21] Saaty, T. L. (2008). Decision making with the analytic hierarchy process, International Journal of Services Sciences, 1(1):83-98.

[22] Saaty, T. L. (2004). Fundamentals of the analytical network process-dependence and feedback in decision-making with a single network, Journal of Systems Science and Systems Engineering, 13(2): 129-157.

[23] Saaty, T. L. (1996). Decision making with dependence and feedback: The analytic network process, RWS Publications, Pittsburgh 